\title{
User-Producer Dialogue, Workplace Innovation, and Knowledge in a Regional Innovation System
}

\author{
Helge Svare
}

Received: 20 February 2014 / Accepted: 17 November 2014 /

Published online: 30 November 2014

C) The Author(s) 2014. This article is published with open access at Springerlink.com

\begin{abstract}
This study aims at creating new knowledge about the connections between regional innovation systems, the enterprises they enclose, and their individual employees in order to better understand the enterprises' innovation processes. A particular focus is directed at the interaction of these employees both within their own enterprises and with individuals and institutions outside them, along with the types of knowledge being involved, and their function in the innovation process. Two research questions are posed: (1) What sort of interaction takes place between individuals inside and outside of an SME when it innovates, within the context of an RIS? and (2) What types of knowledge are involved in this interaction, how are they developed and shared, and what is their function in the innovation process? The study is designed as a qualitative, explorative case study of nine small- and medium-sized enterprises in a Norwegian region. Interaction with customers was identified as the most significant form of interaction driving innovation, and practical knowledge was judged more important than scientific knowledge. This practical knowledge, moreover, was seen as comprising not only production skills but also the practical lifeworld knowledge of customers, and cooperative skills. In addition, a high degree of employee participation in workfloor decisions was judged to promote the innovation process. The paper argues for a revision of the notion of a regional innovation system that takes greater account of these dimensions. Four implications for policy are emphasized: (1) stimulating userproducer interaction within a regional innovation system, (2) involving the right employee groups, (3) utilizing the full potential of various types of practical knowledge, and (4) promoting employee participation within enterprises.
\end{abstract}

Keywords Regional innovation systems $\cdot$ Knowledge $\cdot$ Skills $\cdot$ Dialogue

Work organization

H. Svare $(\bowtie)$

Work Research Institute, Oslo and Akershus University College of Applied Sciences, P.O. Box 4, 0130 Oslo, Norway

e-mail: helge.svare@afi.hioa.no 


\section{Introduction}

Regional innovation system (RIS) theory has long been one of the main theoretical approaches to innovation research and policy in regions (Asheim and Gertler 2005; OECD 1997, 2011; Ekman 2011). Instead of focusing on an individual firm or entrepreneur, RIS theory emphasizes how innovation results from the interaction between actors in regional contexts, especially between enterprises in networks or clusters, and between these enterprises, R\&D institutions, and local government. The term interaction is here used in a broad sense, involving not only the number and frequency of contacts but also their type and quality, that is, their whole institutional, epistemic, and social fabric.

The same emphasis on institutional, epistemic, and social fabric is found in research on the internal dynamics of innovative enterprises in the workplace innovation literature. For instance, research has identified a strong correlation between how enterprises are organized in terms of hierarchies, participation, and problem solving, and how they innovate (Høyrup Pedersen 2012). Thus, the relatively egalitarian work culture found in the Nordic countries, with a large number of highly qualified employees who exercise a high degree of autonomy and participation in workfloor decisions, has been demonstrated to promote a culture of continuous innovation, particularly of an incremental kind. That is, such organizations promote small, stepwise improvements over time, resulting in high-quality products and services that make the Nordic region competitive in spite of high wage and tax levels (Asheim 2011; Arundel et al. 2007).

Thus far, however, few studies have explored the connections between the two fields of institutional, epistemic, and social fabric defined above-i.e., the field represented by the system and that represented by the individual enterprise. Although the claim that such connections exist may be considered a commonplace, few studies have explored more specifically how these work in practice, and if they do, they operate mainly at a macro level and not at the meso and micro level where the internal spaces of the enterprises involved become visible.

The present study addresses this research gap, first by establishing a perspective of continuity between the RIS, considered as a system of interaction between individual enterprises and collaborating organizations, and the internal spaces of these organizations. More specifically, while taking RIS theory as its starting point and exploring how organizations within an RIS interact, this study does not treat these organizations as its smallest units of analysis but extends its investigation into the internal spaces of these units with their institutional, epistemic, and social fabric. Focusing in particular on the internal spaces of small- and medium-sized enterprises (SMEs), it aims to explore how their inhabitants interact among themselves, as well as with inhabitants of other spaces representing other system units. In other words, it aims to identify the relevant interactions, processes, and structures involved in an innovation as one continuous and coherent process, whether taking place within one particular enterprise or involving individuals from other organizations in addition. This study also seeks to explore the key dimensions and aspects of such processes and structures. On this background, it poses the following research questions:

1 What sort of interaction takes place between individuals inside and outside of an SME when it innovates, within the context of an RIS? 
2 What types of knowledge are involved in this interaction, how are they developed and shared, and what is their function in the innovation process?

In order to answer these questions, a qualitative, explorative case study of nine SMEs in a specific region in Norway has been designed. This design is based on the following considerations: The fact that each SME in the study constitutes a case means that the dynamics of the RIS are explored from within the individual enterprises. This opens up for a critical perspective of the RIS due to the fact that enterprise representatives, whose main loyalty is to their enterprise, will probably perceive and evaluate their RIS differently from system members whose loyalties lie more with the system itself, such as cluster organization managers or regional government representatives. The regional basis of the study relates to the methodological norm of context sensitivity, maintaining that local conditions need to be taken into account when attempting to understand the workings of regional innovation systems and, at a later point, also when translating research findings into policy. Finally, even if a qualitative, explorative case study cannot in itself confirm the validity of a general theory, the thick descriptions typically produced from such studies may nevertheless supply valuable insights from which suggestions for theoretical revisions, modifications, or extensions may be inferred. Some such suggestions will be presented in the discussion section of this paper in addition to some policy implications.

\section{Theoretical Background}

The theoretical approach on which this study is based is derived from two major research traditions within current innovation research. The first is RIS theory (Asheim and Isaksen 1997; Cooke 2001; Asheim et al. 2011), which for the sake of simplicity here will include both the Triple Helix theory (Etzkowitz and Leydesdorff 2000) and later extensions of this to Quadruple Helix theory (Arnkil et al. 2010), or even N-tuple Helix theories (Leydesdorff 2012). Although these approaches are not identical, they all share some basic assumptions (see Leydesdorff and Zawdie (2010) and Asheim et al. (2011) for a discussion). The first one is that innovation is distributed, co-evolving from the interactions of several actors in regional contexts. The second assumption is that knowledge and learning are the most significant drivers of innovation (Lundvall and Johnson 1994; Etzkowitz and Leydesdorff 2000; Lundvall and Lorenz 2006) and, consequently, that the long-term development of an RIS must involve smart strategies for knowledge and learning management (Parrilli and Asheim 2012).

The various approaches have diverging views on which categories of actors they view as more significant. While the Triple Helix approach emphasizes interaction between industry, academia, and government, the Quadruple Helix approach also includes civil society or more specifically the users of innovation (Arnkil et al. 2010), thereby also approaching the research tradition emphasizing user participation in innovation (Rosenberg 1982; von Hippel 1988; Grabher et al. 2008) (see Bogers et al. (2010) for an overview). The definition of Doing, Using, and Interacting (DUI) as a separate mode of innovation within innovation systems (national as well as regional) is also relevant here (Lundvall 1988). 
The approaches also differ with respect to what types of knowledge are given priority. While Triple Helix theory tends to ascribe more significance to scientific knowledge, theories focusing on user-producer interaction (inside and outside of an RIS) are prone to give more emphasis to practical, tacit, or sticky (i.e., contextual) forms of knowledge (von Hippel 1994). Lundvall and others give due credit to both with their distinction between the STI and DUI mode of innovation (Berg Jensen et al. 2007; Lundvall and Lorenz 2006). While the STI mode of innovation (Science, Technology, and Innovation) is based on the production and use of codified scientific and technical knowledge, the DUI mode (Doing, Using and Interacting) relies more on tacit knowledge or practical skills and interactional learning, driving incremental innovation in producer-user relationships.

The present study is based on the premise that user-producer interaction is a relevant part of the general interaction within an RIS, and it supports Lundvall's claim that both the STI and DUI modes of innovation are significant.

The second major theoretical approach on which this study is based is the one found within the discourse on workplace innovation (Fricke and Totterdill 2004; Høyrup Pedersen 2012; Totterdill et al. 2009). A basic idea here is how workfloor participation engenders engagement, which again promotes innovation (Ramstad 2009; Alasoini et al. 2008). It is also well documented from other fields of research that collaborative work forms are highly conducive to learning, enhancing a wide variety of skills (see, e.g., Johnson and Johnson (1989)). Norway, along with other Nordic countries, has traditionally been characterized as having a well-developed culture for employee participation, which may be explained by a long history of collaboration between the main partners of the working life, along with large-scale action research projects that have actively aimed at creating a culture for such collaboration and participation (Gustavsen 2011; Qvale 2011).

\section{The Study - the Cases and the Research Design}

The study was initiated and carried out under the Programme for Regional R\&D and Innovation (VRI), a government-sponsored program aimed at strengthening regional innovation systems and promoting innovation among enterprises (Norwegian Research Council 2011). It was designed as a qualitative explorative multi-case study of nine SMEs, with each enterprise constituting a separate case.

The explorative aspect was achieved using a narrative approach in the interviews (Hollway and Jefferson 2000). Each interview was initiated by asking the interviewee to describe briefly how the enterprise had come into being, and its current status, and then to identify an innovation in which the company had been involved, and that had been significant to its development. The rest of the interview was dedicated to the story behind this innovation, with interviewer interventions limited to ensuring that enough details were included in the ensuing narrative, for instance by asking who had been involved in the innovation, how they had contributed, and how other factors had influenced the process. The researchers also made sure that the interviewee included information relating to structures and processes both internal and external to the company. In most cases, the innovation that the interviewee chose to focus on was the innovation on which the enterprise had originally been founded. 
The companies are all located in the district of Telemark in southern Norway. For over a century, Telemark has been one of the most highly industrialized counties in Norway with a high concentration of process industry. Nevertheless, the county is also home to a collection of smaller manufacturers, operating as sub-suppliers to the process industry, and serving markets outside the region. Some of the enterprises serving as cases are located in Grenland, the largest urban area of the county; others are situated in Notodden, a smaller inland town originally built around two large industrial plants. Since the plants were closed some years ago, its economy has diversified and includes, for instance, companies oriented toward Norway's blooming offshore sector. The county has experienced mild recessions following the closure or downsizing of the original industry, and although employment rates have improved with the establishment of new enterprises, the relative significance of the county as an industrial and economic area has been reduced. Telemark has also scored poorly on a number of development indexes compared with the rest of Norway (Vareide and Storm 2011). The county is heavily influenced by working-class culture, but agriculture is also widespread. Even if the county is home to one of the largest university colleges in Norway, there has traditionally been little interaction between its academic staff and the local industry (Sasson 2010). Grenland houses several private R\&D institutes, but the majority of these perform in-house research for their owners, typically industrial corporations, and their services are consequently not accessible to others. In addition to its ties with Grenland, Notodden has traditionally had even stronger bonds with the city of Kongsberg in the neighboring county. Kongsberg is currently home to some of the most robust and dynamic industrial enterprises in Norway.

For the last 10-15 years, the innovation policy of Telemark has been dominated by RIS and cluster theory, and various industrial cluster organizations have been established and supported through the VRI program and other public funding initiatives. The term "cluster organization" here refers to formalized collaborations between enterprises that are either part of a cluster or may have the potential to become one. All the enterprises included in this study were members of at least one such cluster organization. The enterprises in Notodden were also members of a cluster organization in the neighboring county.

In Grenland, three Information and communications technology (ICT) and four manufacturing enterprises were included in the study, with the addition of two manufacturing enterprises in Notodden. The manufacturing enterprises normally offer also maintenance services. Most of the SMEs were about 7-10 years old and were still headed by their founder(s). Table 1 gives an overview of the enterprises with location, founding year, and number of employees.

Most of the enterprises are regional, in the sense that they have regional owners and production facilities located within the region, even if customers may be both local, national, and international. ICT2 has established branches in other areas of Norway, and both ICT3 and MAN4 have been through an expansion process leading to the establishment of national and international branches. MAN3 is part of a multinational enterprise with production facilities both in other regions of Norway and in other countries. A further specification of the types of production carried out by the enterprises has been omitted to preserve their anonymity.

The interviews were conducted in 2012 and 2013. Each interview lasted between 1 and $2 \mathrm{~h}$. In most cases, two or more interviewees were present, most often the head manager, who was usually also the founder and main owner of the enterprise, along 
Table 1 Overview of the enterprises

\begin{tabular}{llrr}
\hline & $\begin{array}{l}\text { Location } \\
\text { G=Grenland } \\
\text { N=Notodden }\end{array}$ & Founded in & Number of employees \\
\hline ICT1 & G & & \\
ICT2 & G & 2007 & 40 \\
ICT3 & G & 1991 & 50 \\
MAN1 & N & 1997 & 100 \\
MAN2 & N & 1970 & 50 \\
MAN3 & G & 1993 & 10 \\
MAN4 & G & $*$ & 140 \\
MAN5 & G & 1994 & 100 \\
MAN6 & $\mathrm{G}$ & 2000 & 4 \\
\hline
\end{tabular}

*The enterprise has traditions back to the nineteenth century and was reestablished after a major bankruptcy in the 1980 s

with his "second-in-command" or another employee of his choice. However, in some cases, the company manager/founder chose to be interviewed alone, or a second interview with another employee was conducted at a later point. In addition to the interviews, background data was also collected from company websites and from newspaper articles and participation by the researchers in a large number of cluster organization meetings and events.

Sampling of cases is generally regarded as crucial to the case study method (Eisenhardt 1989; Yin 2008). In this study, the companies constituting the cases were selected on the basis of their status as innovative enterprises, and many of them had also received rewards in this respect. The actual selection was undertaken with the assistance of the regional branch of the Confederation of Norwegian Enterprise. The sampling also aimed to include cases from more than just one industry.

As with all research methods, data generated through the narrative method will invariably be colored by the method. For instance, more emphasis will typically be placed on individual action than on economic, cultural, or societal structures. In particular, the protagonist of the narrative - usually the narrator himself - will tend to make his presence felt (McAdams et al. 2003). In addition, narratives are typically structured as chronological stories with isolated actions and events woven together into an integrated whole. Finally, the roles of other persons appearing in the narrative are primarily defined in relation to the protagonist and his goals; others, for instance, may be ascribed the role of supporter or adversary (Fenton and Langley 2011).

This also proves true in the interviews conducted for this study. Most of the stories were based on the basic narrative of "how a series of struggles finally led to success due to the persistence of the protagonist(s), " which may well be a narrative that lies close to the objective facts, but which nevertheless contains bias. For instance, the larger context and its significance tended to recede into the background. The questions that targeted this context more directly therefore turned out to be a valuable means of getting a better overall view. 
One potential strength of the narrative approach is the fact that it may provide an indication of the kinds of problems, dimensions, or facts that preoccupy the narrator. While some aspects of reality are merely mentioned incidentally, others evoke long and emotionally charged deliberations. Whether the latter aspects are also objectively more significant cannot be deduced from these deliberations alone; nevertheless, given that they provide insight into the thoughts and emotions of the narrator, they do help to understand how he/she views the world, which may again generate a greater understanding of his/her actions and priorities than what can be deduced using other research methods.

The interviews were transcribed, imported into Weft QDA (standard software for analyzing qualitative data), and then analyzed.

In the first round of data analysis and coding, we employed codes that lay as close as possible to the topics actually discussed by the interviewees. The codes relevant for this study may be organized under the following general headlines:

Codings related to the institutional, epistemic, and social fabric of the company:

- Work organization

- Recruitment policy

- Labor skills

- Internal team culture

Codings related to the innovation, and what had either promoted or obstructed its development:

- The innovation

- What promoted its success

- What obstructed its success

Codes relating to the larger context:

- The region

- Alliances

- Customers

- Cluster organizations

- Research institutions

- Public funding agencies

\section{Findings}

The findings are presented below. The presentation will follow the logic of the headlines listed above with an only slightly modified sequence, beginning with a look at the significance of regional cluster organizations.

The Significance of Cluster Organizations

All of the enterprises involved in the study were members of one or more cluster organizations, which typically comprised regional members of a particular industry. 
Some of the interviewees had also been among the founders of such organizations. Still, when talking about them, the prevailing attitude seemed to be conspicuously lacking enthusiasm or, in some cases, even critical.

This does not mean that the organizations were deemed useless. Notably, when looking back on the cluster organizations' initial years of activity, the interviewees identified several benefits to their enterprises deriving from their involvement. This was especially the case for those enterprises that were recent start-ups at the time. Through the cluster organization, the yet inexperienced company managers met and drew inspiration from each other:

We could talk about everything; how others solved various problems, wage and shareholder policies, programming languages, reciprocal technology exchange - anything that could make life a little easier. If someone needed space for a meeting, another company could sometimes offer it... We helped each other solve all kinds of practical problems. ICT3

The cluster organizations had also fostered a greater community spirit among their members, reducing the incidence of negative competition:

Previously, we held this idea that we were nothing but competitors. But we aren't. We have learned how we may all benefit from pooling resources when the situation is right. [...] After becoming better acquainted with the other enterprises, I feel it's unethical to underbid them when competing for a contract. [...] If we had only been competitors, it would've been easy to think, "How can I destroy them?" It's not that simple now that I know them. That's where ethics comes in. Also, there is no need to compete all the time. There is room enough in the market for all of us. MAN4

The cluster organizations had also given rise to concrete collaborations. For instance, one company bought technology or services from another, while others exchanged labor when one enterprise had more to do than the others:

Through the others, I gain access to skilled labor and extra production capacity when I need it. That's new. MAN4

Lastly, the cluster organizations gave each member the opportunity to present itself to potential customers or other useful contacts, either directly at cluster organization events or by word of mouth:

We made a very important commitment to speaking well of each other. "Their project [another company's] is really exciting," I told Innovation Norway, and because they knew me and knew that I was not bullshitting, I made the entrance of the other company easier. [...] The effect of speaking well of a company is much stronger when praising another business and not your own. ICT3

In addition, of course, cluster organization meetings provided an arena for exchanging other sorts of useful information or for initiating joint learning processes. 
Still, a lack of enthusiasm marked most conversations about the cluster organizations. One reason for this, pointed out by the interviewees, is that they have now grown older, more experienced, and their enterprises more successful, so that the need for exchanging ideas or information feels less acute. Even more significant is the sentiment that the payoff from participating does not measure up to the time invested in the organizations, the typical message being that they had expected more from taking part than what they had actually gotten out of it. More specifically, participation should have contributed more to the continuous development of the company. In none of the cases had a company joined another member in their cluster organizations to initiate a joint innovation project.

Primarily, the enterprise managers seem to be the ones who engage in the cluster organization activities. The explanation, according to some of our interviewees, is either that the rest of the staff has no interest in cluster organization activities or that the managers profit more from taking part in them.

\section{The Innovation Process and the Customer}

Even if the interviewees have no troubles identifying cluster organization benefits, the benefits were judged to be of little immediate relevance to innovation. The contacts and relations that proved relevant in this respect were found elsewhere: For the most part, it was in relation to customers and to product development processes close to customers that innovation occurred, according to the narratives.

The relationship between enterprise and customer was slightly different in the two industries examined. The ICT enterprises produce ICT systems that typically involve a major investment from their customers. The transaction costs associated with changing software providers are significant. Consequently, when a customer first establishes a relationship with a provider, it tends to become long term. Nevertheless, if the software is not continually updated and improved, the customer might still decide to switch to a competing system. Thus, continuous improvement and innovation was part of the daily work in the ICT companies. One company had adopted the policy of launching a new, improved version of their software every sixth month.

The manufacturing companies typically established shorter-term relationships with their customers, and when a longer-term relationship was being established, it typically consisted of a series of discrete transactions, each corresponding to an individual contract.

In both industries, however, certain recurring characteristics were common in relation to customer involvement in the innovation process: Through the innovation process, a dialogue between company and customer was being established in which not only the management level but also - and, perhaps, even primarily - the floor staff were involved. Ideas for improvement could come from both the customers and the producers, including the floor staff. The processes, moreover, conformed to the DUI mode of innovation, involving mostly, but not exclusively, incremental innovation.

For those manufacturers who tailor their deliveries according to predefined specifications from a customer, a normal innovation process was initiated when the customer entered into a dialogue with the company as part of the delivery process, resulting in an improvement of the original concept and, consequently, in a better product. The input to 
the innovation then usually originated on the work floor, coming from those immediately involved in the production.

One manager related that small teams from the customer company would visit the production facility of his company during the design process corresponding to an order. Discussions on how to best realize or improve the design would then typically emerge; discussions in which all his employees might participate with some kind of input.

Another manager reported that his enterprise's business idea was to come up with creative solutions to design challenges the customers lacked the skills or the capacity to solve on their own. His staff of creative designers would then work to find a solution. The ensuing dialogue - as he described-typically became an awareness-enhancing process. That is, successful dialogue resulted in the customer gaining-sometimes gradually - a more specific grasp of his needs and how the proposed design could meet them.

Even if the customer has set out some general specifications for the delivery, his idea of what is needed may be vague, or perhaps his expectations [of what can be achieved] are too modest given what we see as a possibility. Only then, after some time, does the customer acknowledge: "Yes, that's what I want! I hadn't realized it before." MAN9

The ICT companies in our study reported that the discussions emerging when their personnel paid service visits to their customers were essential to their ongoing innovation activity. The initial reason for the visit could be to fix a bug in the system or to solve some other specific problem. Meanwhile, however, the consultants also initiated an informal dialogue with the software users, probing into how well the software worked on a daily basis, how well it answered to their needs, where its weak points were, etc., and whether they had any ideas for improvements. This feedback was then brought back to the company's developers, forming the basis for further incremental innovation.

In some cases, innovation was also developed through systematic dialogue that took place over longer periods of time. In such cases, external funding of some kind was usually available, for instance from a governmentally sponsored R\&D funding scheme. One of the ICT companies carried out an extensive project of this type, during which biweekly dialogue meetings were organized with customer representatives. The result was a radically improved ICT and management system that the company was then able to launch on a global basis.

\section{Type of Knowledge, Skills, and Learning Involved}

In the interviews, knowledge surfaced as a topic in connection with two follow-up questions: First, which groups within the enterprise contributed to the innovation process? Second, which factors were emphasized when new staff was employed?

In both cases, answers disclosed that the highest priority and the greatest value were attributed to practical knowledge and skills relating to the core activity of the enterprise or, alternatively, to the core activity of the customers. Theoretical knowledge of the type accrued as part of a university education was explicitly ascribed less significance. One interviewee put this rather bluntly, claiming that university graduates were needed in 
meetings with potential customers, because "the company is expected to possess such expertise"; however, the "real job" was executed by those with practical knowledge and skills, who had mostly little or no formal education. He elaborates further:

My academic credentials are merely an alibi. [...] It gives me a certain credibility... When I meet a customer, "Bill" is ten times more qualified than I am. He could well have conducted the whole meeting alone. However, he has no papers to document his skills. [...] I could send out a team of such persons. They would be brilliant, but without formal credentials, people don't take them seriously. MAN4

The ideal recruit in the manufacturing cases was described as someone "whose work is also his hobby" in the sense that he should enjoy working with his hands in his free time. A favorite candidate would be a man who has spent his adolescence fixing bikes, cars, or other things and thus has a long history of tinkering. Alternatively, he could have a background from a small farm:

We want to find the people who think it's fun to fix motorbikes. And they need common sense. People who have grown up on a farm are also good. They have a certain perspective that not so many have... if you don't do anything and take no initiative, then nothing happens, nothing is created. MAN1

When requested to describe his "ideal employee," another interviewee responds:

He or she has to be practical. And they should be curious... interested... Formal, technical knowledge is less important. Those with a formal education may not be the best ones. It is most significant that they are genuinely interested in the type of work being done here. There is this guy... He works a full day here, and then he goes home and continues doing exactly the same thing in his own workshop. Many of the workers here are like that. Their hobbies are within the same field as here at work. MAN2

The reason this type of employee is valuable to the workplace, also when it comes to innovation, is their initiative. It enables them to act independently or collectively when a challenge arises during a work or design process instead of waiting passively to be told what to do. In addition, their experience and practical knowledge have given them a special eye for functionality that is indispensable for developing better and more functional solutions, both in the form of ideas and in the actual implementation. Thus, one of our interviewees reports how one of his employees might follow up on a meeting with a customer:

We have this employee... A customer may come with an idea for some improvement, and this man then goes directly from the meeting down to the workshop, perhaps to make a physical model to illustrate the customer's idea or to test it out. Then he may report back to the customer. MAN4

The ideal ICT recruit is a young person who has been passionate about computers since childhood and through this has acquired practical programming skills that no 
formal education can rival. In addition, the ICT recruiters look for persons with practical skills and everyday insights that define the core activity of their customers. This latter point relates to the fact that successful ICT enterprises are those able to produce systems that support customer enterprises in what they do. Thus, in order to innovate, they have to be able to grasp the logic inherent in their customers' practices.

One of the narratives related by the founder of one of the ICT enterprises is informative in this respect. His company is based on one main innovation: a complete workflow surveillance and management system adapted to workplaces within a specific type of industry. In developing this system, he performed a number of quasiethnographic field studies at a number of workplaces within this industry. He recounts how, for instance, during a visit to another city, he spent the whole day walking the corridors of such a workplace, observing how the staff performed their duties, and entering into informal dialogue with the people that he met about the ways and routines of the place. He also observed how certain groups of employees were periodically prevented from proceeding with their tasks until another group had completed their own, and how much time was wasted due to such impediments. It was through such observations and discussions, he explained, that he gained a grasp of the complex nature of this particular type of workplace and the challenges involved in coordinating the various activities taking place there. Moreover, this was the background on which his vision of the new system emerged.

We may notice that it was by observing the system in practice that he acquired the knowledge necessary for his innovation, and also that his insight into this practice was derived from dialogue with practitioners. It was by talking to people in the midst of performing their practical tasks, he emphasized, and only then, that he acquired the knowledge he needed. In addition, those who contributed the least to this knowledge were the managers, while those who contributed the most were the practitioners lower down in the workplace hierarchy. Thus, at a later point when his company established an $R \& D$ project to further develop the system in cooperation with a workplace in another Nordic country - the "Nordic project"- he saw to it that all professions and workgroups at this workplace were represented in the project group, including practitioners from lower levels of the work organization.

Another ICT enterprise signals its recognition of practical skills and experience by recruiting practitioners from the business field they serve, and then by placing them in positions that allow them to communicate extensively with both their customers and with their colleague programmers. The underlying rationale for this recruitment and management practice is that only a previous background in the company's operational field will enable a company employee to notice or understand the real needs and challenges pertaining to this field-i.e., those of their customers.

\section{Floor Staff Involvement and Non-hierarchical Organization}

As already implied in the above account, the floor staff contributes significantly to innovation processes in all the companies involved in this study. In some cases, this involvement is institutionalized through fixed routines, such as when one of the ICT enterprises uses a project management system that demands the whole workplace to become involved at predefined milestones in a project development process. The project group then presents their preliminary results in an all-hands meeting and 
receives feedback from the others. In other cases, involvement is more informal and spontaneous, as when an employee asks a colleague for input or help whenever it is needed.

This also illustrates the relative non-hierarchical nature of the innovation processes within the companies. In most cases, the collaborations involve relationships that cross boundaries that might otherwise exist between workplace hierarchies or professions. In addition, employees on all levels have a significant degree of autonomy in the processes. Actually, as witnessed, employees that take individual initiative are actively sought after when enterprises recruit new employees.

Consequently, floor staff involvement, participation, and non-hierarchical work processes are indicated as highly significant factors when our interviewees are asked to account for the innovative capacity of their enterprises. One of the enterprises is part of a multinational company with production lines in several countries. The significance of the said factors is especially emphasized here. The interviewee reports how the company's foreign production lines lag behind the Norwegian ones when it comes to incremental innovation. In these other countries, due to more hierarchical work relations, engineers and blue-collar workers seldom communicate face to face, except during short meetings. Moreover, when an unforeseen challenge arises in the production process, the blue-collar worker seldom acts independently to solve it, waiting instead to be told what to do from higher management levels. This means that the whole process drags out over time and that the outcome frequently turns out to be less than optimal due to barriers of communication along the way. In the Norwegian production line, on the other hand, the entire workforce is present in the same environment; they communicate freely and join forces to solve a problem spontaneously when an unforeseen problem arises, leading not only to quick problem solving but also to a high frequency of incremental innovation. Here is how one of the managers summarizes the point in question:

Things break down if you don't allow everyone to have a say. [...] Of course, we have a project management system. But our workers are so skilled... so there is no need for rigid control regimes. That's what's so different [in the Norwegian work culture]. The point is that each and every one takes charge. That's why we are so good at delivering in time. That's why we are competitive, in spite of the higher Norwegian wages. [...] Also, with such skills, the ordinary worker gets ideas on how to improve things more frequently. MAN3

This quote also relates to the discussion of knowledge and innovation: Due to the non-hierarchical work processes, the knowledge base of the various groups and professions involved in the production develops positively. While engineers acquire more practical skills, blue-collar workers-through continuous dialogue with the engineers - are able to access some of their expertise. Thus, all those involved in the production become increasingly better qualified. The manager explains:

The Norwegian engineer is second to none. [...] And he is flexible. He does not merely master his own field of work, he also knows a bit about other parts of the production line. He understands the interface of the project, how it is all connected. [...] I guess the same applies to the other workers as well. You have your 
field of expertise, but you also have some knowledge in other fields. Thus, you have an overall understanding of the product, what needs to be in place for everything to work. And you know who to ask if something is missing. [...] If you compare us with XXX [mentions a plant in another country], it's almost as if the people there are wearing blinders. A mechanic working with a part attends only to that part and takes no interest in what it's going to be connected to. [...] Here everyone takes responsibility for the whole product.

\section{Academic Knowledge and R\&D Collaboration}

The enterprises observed in this study have mixed experiences from collaboration with R\&D institutions. Some have positive experiences and collaborate with such institutions on a regular or quasi-regular basis. Still, when referring to "researchers in general," our interviewees complain that they often seem to have their own agendas when entering joint $R \& D$ projects and that these are not necessarily optimally suited to the enterprise's. In one case, an interviewee had a feeling that his company had been exploited by the R\&D institution. He explains:

We once joined in on a project that had been granted several million NOK in funding from the EU. The project was led by a Norwegian R\&D institution and had partners in six countries. We never saw the money nor did we register any useful results from the project. The only thing we did end up with was a bill for one million NOK [EUR 120 000]. Whenever the project group met, things were discussed in the vaguest terms possible. Never again will we have anything to do with them! MAN2

Researchers were also criticized for their lack of market orientation, for not recognizing how most young SMEs need quick returns on their investment in innovation, or failing to acknowledge that the ongoing innovation process may only be financed from such returns:

Their interest lies only in developing new things. They have no concern about whether there is actually a market for what is being developed. ICT1

\section{The Regional Support System}

Governmental agencies represent a significant part of an innovation system, according to Triple-Helix theory. In Telemark, this part of the innovation system is present in the form of Innovation Norway, a publicly funded agency helping businesses through advisory services and financial support schemes. In addition, various other financial support schemes are available, such as those administered by the Research Council of Norway. Finally, the regional government has a department for regional development that is responsible, among other things, for designing a coherent development strategy for the county as a whole together with the local enterprises. Most of the enterprises in the study have positive experiences with one or several of the financial support 
schemes. For some of the enterprises, such schemes were a pivotal part of the start-up process. Such schemes are also frequently employed to support innovation. The advisory service offered by Innovation Norway mostly receives positive evaluations.

\section{Discussion}

The following discussion includes a series of reflections pertaining to the main findings referred to above.

\section{User-Producer Interaction}

The first reflection relies on the general finding - conforming also to the basic idea of RIS theory - that innovation is distributed. More particularly, however, it relates to the fact that in none of the nine cases does this distribution seem to include partners in cluster organizations, and collaboration with $\mathrm{R} \& \mathrm{D}$ institutions appears also to play, at best, a secondary role. Conversely, the innovations focused at in all the nine cases are driven by user-producer interaction.

In the literature on user-producer interaction, several reasons are given for why such interaction may be significant to innovation. One reason derives from the very distinction between innovation and invention (Schumpeter 1950). In order for an invention to become an innovation, it has to meet a market demand. In order for an enterprise to successfully innovate, either it has to convince the market to buy the new "something" it has developed or it has to detect or gain knowledge of some hitherto unmet need in the market and then develop a new "something" that meets this demand. Thus, some kind of communication or interaction with the market (i.e., users) is essential.

A related argument is that few SMEs can afford the costs involved in innovation with no return over an extended period. Actually, for a young SME with a low capital base, a return should come as quickly as possible, as there is frequently no way to finance further innovation without finance. A relevant response may therefore be to pursue innovation in an existing customer relationship.

Innovating close to customers, or in cooperation with customers, may also be profitable to the innovating company because the customer may be inclined to invest a significant amount of non-financial resources in the innovation process, primarily in the form of ideas or knowledge (von Hippel 1988). For the customers, such investments may be motivated by an interest in having the innovation produce optimal customer value. Such knowledge and ideas may, however, also be of significant value for the innovating enterprise, which gains knowledge at a minimal cost that it would otherwise have had to pay for or develop itself. If the knowledge is "sticky," that is, contextual and mainly tacit, and consequently difficult to transfer from one context to another, the involvement of the customer becomes even more essential (von Hippel 1994).

The enterprises included in this study all conform to - and explicitly refer to- the logic here suggested, for instance related to the necessity of quick return on investments in innovation processes. Even more, the interviewees acknowledge the value of the information derived from their customers - potential as well as actual — admitting how it is essential for their ability to innovate. 
This study produces new knowledge on the area of user-producer interaction by adding to the picture of how this interaction is organized. It occurs in informal dialogues when users visit the production facilities of producers; it develops through quasi-ethnographic studies performed at workplaces representing actual or potential customers, and through formalized dialogue processes during product development processes.

Actually, in all of the nine cases, the corresponding companies seem to have succeeded remarkably well in establishing productive forms of knowledge exchange with their customers. Even if knowledge sharing has a cost (in terms of time) that is explicitly acknowledged by all the participants, relationships with customers have nevertheless been built in which such sharing takes place. In some cases, exchanges occur so smoothly that the customer may not even reflect upon the fact that sharing is taking place, as when the consultants from the ICT enterprises initiate informal dialogues about their software during service visits.

This study also draws light on the productive atmosphere that may emerge when the partners become so engaged in an innovation dialogue that they seem to "forget" whether they represent the producer or the customer side of a relation, and instead become immersed in the development process itself. One may, of course, assume that the partners have vested interests in the outcome of such a process. However, such interests are not emphasized in the narratives. Rather, they convey a feeling of community, and the mere joy of being part of a creative process. They describe a state of being coming close to what some theorists define as "flow" (Csikszentmihalyi 1990).

One of the conditions for this flow may be found when examining the case of the ICT company carrying out the Nordic project. Significant to this project was the fact that it received financial support from a research agency that made it possible to allocate more time to the dialogue. The support also removed some of the financial pressure that the collaborators could otherwise have experienced. Both factors may have helped build better relationships. The financial support may also have fostered a feeling of being partners in a joint project.

Another condition for the flow, derived from the narratives, may be similarity. The similarity may relate to the professional background: A dialogue seems to become more engaged when people with a similar professional background meet. One of the manufacturing enterprise cases exemplifies this: The customer representatives that visited the plant during a production process had the same professional background as both the manager of the plant and its production workers. The outcome was a highly productive dialogue. The similarity may also relate to culture: One ICT enterprise had learned, for instance, that when they had won their first major contract — which was to become a turning point in their user-driven innovation process-it was also because they were locals and therefore appeared more trustworthy to the customer. Trust, as is known from previous research, promotes the quality of knowledge sharing and learning in groups (Abrams et al. 2003).

\section{Knowledge}

The second reflection relates to the finding, also conforming to previous research, that knowledge is a significant driver for innovation. It may be worth noting, however, that 
the knowledge identified as most relevant in the nine cases is not the knowledge usually pointed out in public debates or policy statements on innovation, i.e., research-based knowledge. It is the practical knowledge of employees on the work floor. That such knowledge is significant for innovation has also been acknowledged by innovation theory (Berg Jensen et al. 2007; Lundvall and Lorenz 2006). The present study contributes to this theory by emphasizing how complex and multidimensional this practical knowledge is.

One significant dimension is the practical skills required along the production line. This relates to everything, from being able to construct prototypes, to designing and adjusting the manufacturing technology involved in establishing new production lines. In addition, there are the skills involved in quickly seeing or assessing the functionality of a product or production process that in part seems to depend on experience, but perhaps also on some personal talent. This kind of knowledge comes close to the Aristotelian notion of techné or craftsmanship (Lenk and Moser 1973). Another and equally significant dimension is what may be termed "lifeworld" (Lebenswelt) knowledge related to the part of the market that the company is targeting. The term "lifeworld" has here been borrowed from the philosopher Edmund Husserl and refers to the immediate, everyday knowledge about a part of the world in which a person isso to speak - at home (Husserl 1970). The lifeworld of a medical doctor includes hospital life as he knows it through his professional activities, which may overlap in part with, though not equal the lifeworld of nurses, due to the fact that they partake in hospital life differently. The significance of lifeworld knowledge for innovation is perhaps best seen in the ICT cases. In order to succeed, the ICT companies cannot merely rely on the programming skills of their employees; they also need to access the lifeworld of their customers, and primarily in its practical aspect. They need to obtain knowledge into the tasks handled by their customers and their inherent, pragmatic logic. The other cases, however, are not radically different. The manufacturing companies are able to develop products that answer the needs of their customers because they too possess knowledge about relevant aspects of their lifeworld.

A third dimension is what may be called cooperative or collaborative skills, i.e., those skills enabling the collaborative mode of work referred to in the narratives. Knowledge may also be seen as a significant dimension of the "person who takes charge," e.g., the person who does not need to be told what to do but initiates problem solving either individually or collectively. This is viewed not only as a personal trait but also as a skill that can be learned from experience, for instance through growing up on a farm. Interest, involvement, and curiosity - all emphasized as desirable qualities in an employee by the interviewees - are also relevant to the present discussion. They perhaps do not represent knowledge per se but are still closely associated with knowledge, encompassing the passion that stimulates people to constantly seek greater understanding and to improve their skills, individually and in teams.

\section{Knowledge Building}

The third reflection relates to how the sort of multi-dimensional knowledge that was referred to above may be built within the enterprise, namely through designing and maintaining the specific work organization that has been identified in the nine cases. This finding is worthy of emphasis: a non-hierarchical work culture, with a high 
number of highly qualified employees granted a high degree of autonomy and participation in work floor decisions, and the informal collaborative problem solving initiatives that occur "spontaneously" in such a working environment, not only seem to enhance innovation; it also functions as a "learning laboratory" in which ever more sophisticated collaborative and professional skills are being developed, skills that in the next round may enable even more innovation. This point also conforms to numerous studies of collaborative learning that have proven that collaborative, non-hierarchical forms of learningrather than competitive or individualistic forms - serve not only to further promote collaboration as such but also to further enhance the collaborative and professional skills of participants (Johnson and Johnson 1989). The MAN3 narrative in the study may be seen as one example of this: Through teamwork, every participant develops a flexible understanding of the project, of "how it is all connected" and, consequently, more than one team member may respond to a problem and initiate a new, innovative solution.

\section{Floor Staff Participation}

The fourth reflection concerns which specific groups of employees are involved in the user-producer interaction. A central group in this respect is the group of practically skilled enterprise employees. Returning to RIS theory and viewing the internal space of enterprises as part of the system, it may be stated that practically skilled company employees are vital members of the system. This includes, not exclusively, yet essentially, the floor staff directly involved with the production line in the innovating enterprises.

\section{Policy Implications}

The study has implications for innovation policy. Four such implications will be emphasized below.

The first implication relates to the fact that in Norway, as in the rest of the Western world, cluster theory and innovation system theory (mostly in its Triple Helix-version) have formed the basis for designing national and regional innovation policies for over a decade. A significant aim of such policies has been to promote the initiation or development of cluster organizations with members that are somehow "similar," i.e., from the same industry, or on the same level in the value chain. The cluster organizations in Telemark all reflect this logic: each cluster organization recruits enterprises from a separate industry with partly overlapping production technologies and markets. The present study does not support the general conclusion that such organizations are suboptimal means for creating more innovation. It does support, however, the somewhat weaker proposition that such organizations need smart strategies to overcome the inertia that may emerge when such organizations loose the energy that often accompany their first years. The first implication of the study is that designing and implementing smart strategies for user-producer interaction may be part of such a strategy.

The second implication is that policy design should acknowledge that skilled workfloor staff may contribute significantly to innovation processes, and measures should consequently be taken to promote RIS interaction not only at management level but also at designer or production staff level. In user-producer interaction 
where the user is a sub-supplier, it seems particularly momentous that the workfloor staff of both parties interact. A study from Norway, for instance, has demonstrated that when an enterprise give their purchase department monopoly on communication with their sub-suppliers, it becomes harder for their sub-suppliers to innovate, among other things because the purchase department staff lack the professional background to enter into a qualified dialogue with their sub-suppliers' designers and production workers (Lærkerød 2010).

The third implication relates to knowledge. Current innovation policies emphasize almost exclusively scientific knowledge as an innovation driver. The present study does not support the general claim that such knowledge is irrelevant to innovation, even though the interviewees in the nine cases express some reservations regarding the value of academic credentials and also regarding collaboration with researchers. The significant implication, however, is that the importance of practical knowledge or experience should not be ignored by policy makers. Today, public discourse on innovation is almost entirely dominated by a call for higher education and for advanced scientific knowledge production. While such emphasis may well be legitimate, the present study demonstrates that other forms of knowledge may also be essential and that systems and strategies should be designed to maintain and develop them.

The latter point deserves a special emphasis, as such other forms of knowledge are currently under threat in a multitude of ways through the increased academization of the educational system, cultural changes in the population at large with fewer and fewer young people "tinkering" (reported by our interviewees), and the rapid decline in the status conferred to manual labor in general (Stokes and Wyn 2007; Brunstad 1998). Furthermore, when public discourse unilaterally emphasizes the value of higher theoretical education programs while ignoring the element of creativity and play in industrial production, it runs the risk to further demotivating talented young people from building careers based on practical knowledge.

The fourth implication is that policy makers should acknowledge the fact that the non-hierarchical work processes prevalent in Norway and other Nordic countries have a significant knowledge dimension that is conducive to innovation, and strategies should be designed to protect and maintain such processes in a globalized world.

\section{Limitations and Need for Further Research}

The fact that the present study is limited to one single region and a restricted set of cases naturally represents a limitation. Its findings may be an outcome of specific regional conditions to such a degree as to limit general interest. For instance, the fact that academic or scientific knowledge seems to have so little value to our interviewees, or the fact that research seems to play such a weak role in the innovation processes, may be due to the strong working class culture of the region, where practical skills are traditionally valued over academic or scientific knowledge. Alternatively, the type of enterprises included in the study may have created limitations: Previous research has shown that the significance of formal R\&D in innovation in low- and mediumtechnology sectors is lower than in other sectors (Arundel et al. 2007). Studying other regions or including cases from other industries might therefore have produced different results. Further research is needed to confirm or disprove this. 
The finding that an enterprise's membership in a cluster organization seems to be of little immediate relevance to its innovation processes may also be ascribed more to the specific cluster organizations that the interviewees refer to, than to such collaborations themselves. There are examples of similar cluster organizations in other regions promoting innovation among their members (for a Norwegian example, see, e.g., Gausdal and Nilsen (2011)). The difference likely relates to the question of how collaborations are designed in such organizations and what kinds of activities are given priority. Here, as well, more research is needed on how such differences promote or hinder innovation.

Finally, the relative significance for innovation of the various forms of practical knowledge identified in this study, along with the conditions for their maintenance and development, should be explored through further studies employing a variety of methodological approaches, both qualitative and quantitative.

\section{Conclusion}

The research questions of this study were (1) What sort of interaction takes place between individuals inside and outside of an SME when it innovates, within the context of an RIS? and (2) What types of knowledge are involved in this interaction, how are they developed and shared, and what is their function in the innovation process? To answer these questions, a qualitative, explorative case study of nine SMEs in a Norwegian region was designed. Interaction with customers was identified as the most significant form of interaction driving innovation, and practical knowledge was judged more important than scientific knowledge. Furthermore, this practical knowledge was seen as comprising not only production skills but also the practical lifeworld knowledge of customers, as well as cooperative skills. In addition, a high degree of employee participation in workfloor decisions was deemed to promote both the said type of knowledge and the innovation process. This paper argues for a revision of the notion of a regional innovation system that takes greater account of these dimensions. Four implications for policy are drawn, with the basic point that future innovation policies should focus on (1) how to stimulate user-producer interaction within an RIS to promote innovation, (2) how to involve the right employee groups in this interaction, (3) how to develop and bring out the full potential of the various types of practical knowledge pointed at in the study, and (4) how to promote the public acknowledgement of the fact that the non-hierarchical organization of work prevalent in Norway has a significant knowledge dimension that is conducive to innovation and how to protect and maintain this form of organization in a globalized world.

Open Access This article is distributed under the terms of the Creative Commons Attribution License which permits any use, distribution, and reproduction in any medium, provided the original author(s) and the source are credited.

\section{References}

Abrams, L. C., Cross, R., Lesser, E., \& Levin, D. Z. (2003). Nurturing interpersonal trust in knowledgesharing networks. Academy of Management Executive, 17(4), 64-77. 
Alasoini, T., Heikkila, A., Ramstad, E., \& Ylöstalo, P. (2008). High-involvement innovation practices at Finnish workplaces. International Journal of Productivity and Performance Management, 57(6), 449459.

Arnkil, R., Järvensivu, A., Koski, P., \& Piirainen, T. (2010). Exploring Quadruple Helix. Outlining useroriented innovation models. Tampere: University of Tampere, Institute for Social Research.

Arundel, A., Lorenz, E., Lundvall, B.-Å., \& Valeyre, A. (2007). How Europe's economies learn: a comparison of work organization and innovation mode for the EU-15. Industrial and Corporate Change, 16(6), $1175-1210$.

Asheim, B. T. (2011). Learning, innovation and participation: Nordic experiences in a global context with focus on innovation systems and work organization. In M. Ekman, B. Gustavsen, B. T. Asheim, \& $\varnothing$. Pålshaugen (Eds.), Learning regional innovation: Scandinavian models (pp. 15-49). Basingstoke: Palgrave Macmillan.

Asheim, B. T., \& Gertler, M. S. (2005). The geography of innovation: regional innovation systems. In J. Fagerberg, D. C. Mowery, R. R. Nelson, B. T. Asheim, K. Bruland, \& S. Grodal (Eds.), The Oxford handbook of innovation (pp. 290-317). Oxford: Oxford University Press.

Asheim, B. T., \& Isaksen, A. (1997). Localisation, agglomeration and innovation: towards regional innovation systems in Norway? European Planning Studies, 5(3), 299-330.

Asheim, B. T., Smith, H. L., \& Oughton, C. (2011). Regional innovation systems: theory, empirics and Policy. Regional Studies, 45(7), 875-891.

Berg Jensen, M., Johnson, B., Lorenz, E., \& Lundvall, B. Å. (2007). Forms of knowledge and modes of innovation. Research Policy, 36(5), 680-693.

Bogers, M., Afuah, A., \& Bastian, B. (2010). Users as innovators: a review, critique, and future research directions. Journal of Management. doi:10.1177/0149206309353944.

Brunstad, P. O. (1998). Ungdom og livstolkning: en studie av unge menneskers tro og fremtidsforventninger. Trondheim: Tapir.

Cooke, P. (2001). Regional innovation systems, clusters and the knowledge economy. Industrial and Corporate Change, 10, 945-974.

Council, N. R. (2011). Programme for Regional R\&D and Innovation (VRI)—innovation through cooperation. Oslo: Norwegian Research Council.

Csikszentmihalyi, M. (1990). Flow: the psychology of optimal experience. New York: HarperPerennial.

Eisenhardt, K. M. (1989). Building theories from case-study research. Academy of Management Review, 14(4), 532-550.

Ekman, M. (2011). Learning regional innovation: Scandinavian models. Basingstoke: Palgrave Macmillan.

Etzkowitz, H., \& Leydesdorff, L. (2000). The dynamics of innovation: from National Systems and "Mode 2" to a Triple Helix of university-industry-government relations. Research Policy, 29, 109-123.

Fenton, C., \& Langley, A. (2011). Strategy as practice and the narrative turn. Organization Studies. doi:10. $1177 / 0170840611410838$.

Fricke, W., \& Totterdill, P. (2004). Action research in workplace innovation and regional development. Amsterdam: John Benjamins Pub.

Gausdal, A. H., \& Nilsen, E. R. (2011). Orchestrating innovative networks. The Case of 'HealthInnovation'. Journal of Knowledge Economy. doi:10.1007/s13132-011-0070-7.

Grabher, G., Ibert, O., \& Flohr, S. (2008). The neglected king: the customer in the new knowledge ecology of innovation. Economic Geography. doi:10.1111/j.1944-8287.2008.tb00365.x.

Gustavsen, B. (2011). The Nordic model of work organization. Journal of the Knowledge Economy, 2(4), $463-480$.

Hollway, W., \& Jefferson, T. (2000). Doing qualitative research differently: free association, narrative and the interview method. London: Sage.

Høyrup Pedersen, S. (2012). Employee-driven innovation: a new approach. Basingstoke: Palgrave Macmillian.

Husserl, E. (1970). The crisis of European sciences and transcendental phenomenology: an introduction to phenomenological philosophy. Evanston, Ill.: Northwestern University Press.

Johnson, D. W., \& Johnson, R. T. (1989). Cooperation and competition: theory and research: Interaction Book Co.

Lærkerød, S. A. (2010). Kunnskapsutvikling i leverandørnettverk: sertifiseringsregimet som kilde og hinder til kunnskapsutvikling. Bergen: Samfunns- og næringslivsforskning.

Lenk, H., \& Moser, S. (Eds.). (1973). Techne, Technik, Technologie: philosophische Perspektiven. Pullach: Verlag Dokumentation.

Leydesdorff, L. (2012). The Triple Helix, Quadruple Helix, ..., and an N-Tuple of Helices: explanatory models for analyzing the knowledge-based economy? Journal of the Knowledge Economy, 3, 25-35. 
Leydesdorff, L., \& Zawdie, G. (2010). The Triple Helix perspective of innovation systems. Technology Analysis and Strategic Management, 22(7), 789-804.

Lundvall, B.-A. (1988). Innovation as an interactive process: from user-producer interaction to the national system of innovation. In G. Dosi et al. (Eds.), Technical change and economic theory (pp. 349-367). London: Pinter.

Lundvall, B.-Å., \& Johnson, B. (1994). The learning economy. Journal of Industry Studies, 1, $23-42$.

Lundvall, B.-Å., \& Lorenz, E. (2006). How Europe's economies learn: coordinating competing models. Oxford: Oxford University Press.

McAdams, E. E., Lieblich, A., \& Josselson, R. (2003). Up close and personal : the teaching and learning of narrative research. Washington: American Psychological Association.

OECD. (1997). National Innovation Systems. Paris: OECD.

OECD. (2011). Regions and Innovation Policy. OECD Reviews of Regional Innovation. Paris: OECD.

Parrilli, M. D., \& Asheim, B. T. (2012). Interactive learning for innovation: a key driver within clusters and innovation systems. Basingstoke: Palgrave Macmillan.

Qvale, T. U. (2011). Participative democracy and the diffusion of organizational innovations: the long, winding road from a plant level 'field experiment' to regional economic development. In M. Ekman, B. Gustavsen, B. T. Asheim, \& Ø. Pålshaugen (Eds.), Learning regional innovation: Scandinavian models (pp. 187-205). Basingstoke: Palgrave Macmillan.

Ramstad, E. (2009). Promoting performance and the quality of working life simultaneously. International Journal of Productivity and Performance Management, 58(5), 423-436.

Rosenberg, N. (1982). Learning by using. In N. Rosenberg (Ed.), Inside the black box: technology and economic (pp. 120-140). Cambridge: Cambridge University Press.

Sasson, A. (2010). Et kunnskapsbasert Grenland. Oslo: BI.

Schumpeter, J. A. (1950). Capitalism, socialism and democracy. London: Unwin University Books.

Stokes, H., \& Wyn, J. (2007). Constructing identities and making careers. Young People's Perspectives on Work and Learning. International Journal of Lifelong Education, 26(5), 495-511.

Totterdill, P., Exton, O., Exton, R., \& Sherrin, J. (2009). Workplace innovation policies in European countries. UK Work Organisation Network: Nottingham.

Vareide, K., \& Storm, H. N. (2011). Nceringsutvikling, innovasjon og attraktivitet Telemark. TF-Notat (Vol. 41). Telemarksforskning: Bø i Telemark.

von Hippel, E. (1988). The sources of innovation. New York: Oxford University Press.

von Hippel, E. (1994). "Sticky information" and the locus of problem solving: Implications for innovation. Management Science, 40, 429-439.

Yin, R. K. (2008). Case study research: design and methods. Thousand Oaks: Sage. 